\title{
KARAKTERISTIK RUANG PARKIR DI PUSAT PERBELANJAAN JALAN TANJUNGPURA KOTA PONTIANAK
}

\author{
Silvia Jocunda ${ }^{1}$; Yudi Purnomo \\ ${ }^{1}$ Mahasiswa program studi Arsitektur, Fakultas Teknik Universitas Tanjungpura, Indonesia \\ ${ }^{2}$ Staf pengajar program Arsitektur, Fakultas Teknik Universitas Tanjungpura, Indonesia \\ silviawanshan88@gmail.com
}

\begin{abstract}
ABSTRAK
Parkir merupakan tempat pemberhentian kendaraan di suatu kawasan atau bangunan, dimana masyarakat melakukan berbagai aktivitas. Pusat aktivitas untuk masyarakat agar bisa melakukan berbagai aktivitas dapat berupa kawasan pusat perbelanjaan. Daya tarik kawasan dengan tingkat mobilitas barang dan manusia, menciptakan pergerakan lalu lintas yang padat di kawasan tersebut. Peningkatan kebutuhan ruang parkir yang tidak diikuti oleh peningkatan ketersediaan kapasitas ruang parkir di pusat perbelanjaan, berpotensi menyebabkan permasalahan seperti kemacetan arus lalu lintas karena adanya kendaraan yang parkir di fasilitas umum seperti trotoar dan bahu jalan, kerawanan kecelakaan lalu lintas, penurunan kualitas pelayanan jalan, dan lain-lain. Pemahaman tentang ruang parkir di pusat perbelanjaan diperlukan semua stakeholders yang berfungsi sebagai referensi perencanaaan ruang parkir yang baik di kawasan dan bangunan. Tujuan dari penelitian ini adalah untuk mengetahui dan menjelaskan ruang parkir di suatu pusat perbelanjaan. Metode penelitian yang digunakan adalah analisis non-statistik dan statistik dengan menganalisis karakteristik parkir, pola parkir, kapasitas jalan, dan tingkat pelayanan jalan. Lokasi penelitian berada di pusat perbelanjaan yang terletak di Jalan Tanjungpura, Kota Pontianak. Dari penelitian ini ditemukan hasil bahwa karakteristik ruang parkir pada kawasan pusat perbelanjaan dipengaruhi oleh pola aktivitas kegiatan bongkar muat barang dan durasi parkir kendaraan pengangkut barang serta pola aktivitas kegiatan berbelanja pengunjung yang menggunakan mobil penumpang. Penataan menggunakan pola parkir dengan sudut $0^{\circ}$ di badan jalan akan meningkatkan kapasitas jalan. Pusat perbelanjaan dengan model shopping street akan menarik jumlah pergerakan kendaraan lebih kecil jika dibandingkan dengan model department store. Jenis parkir on street di pusat perbelanjaan (shopping street) memiliki tingkat efektivitas pergantian kendaraan yang parkir lebih baik jika dibandingkan dengan jenis parkir off street di pusat perbelanjaan seperti department store.
\end{abstract}

Kata kunci: Parkir, Pusat Perbelanjaan

\begin{abstract}
Parking lot is a place where vehicle stop in an area or a building, where people perform various activities. The center of activity for people may form into several kinds; one of them is shopping center. Mobility level of goods and people in the shopping center, creating a heavy traffic movement in/out of area/building. The increased needs for parking spaces that are not followed by the availability of parking space in shopping center will potentially cause problems. The problems are: traffic congestion as the consequence of parking at public facilities (sidewalks and paving), accidents, the quality reduction of service roads, etc. Knowledge about "parking spaces" in the shopping center is needed by stakeholders as a reference to planning a good parking space for building/area. The purpose of this study is to investigate and explain the parking space at shopping center. The methods of this research is non-statistical and statistical analysis, used to analyze the characteristics of parking, patterns, road capacity and level of service. The research location is in the shopping center located at Jalan Tanjungpura Pontianak. The results of this study discover that the characteristic of parking lot in shopping center of Tanjungpura street are influenced by the activities pattern ofloading/unloading goods and the durations of cargo car parks, and the visitor's shopping activities with passenger car. On-street parking will increase the road capacity by arrange it with $0^{\circ}$ parking pattern. Shopping center with shopping street model attract more smaller vehicles movement if compared to department store model. On-street parking in shopping street has a better turnovers effectiveness rate rather than off-street parking in the department store.
\end{abstract}

Keywords: Parking, Shopping Center 


\section{Pendahuluan}

$\begin{array}{cc}\text { Parkir } & \text { merunakan temnat } \\ \text { nemberhentian } & \text { kendaraan di suatu } \\ \text { kawasan } & \text { dimananan }\end{array}$ masyarakat melakukan berbagai aktivitas. Pusat aktivitas masyarakat dapat berupa kawasan pusat perbelanjaan. Daya tarik kawasan dengan tingkat mobilitas barang dan manusia yang tinggi, menciptakan pergerakan lalu lintas yang padat di kawasan. Akibatnya, terjadi peningkatan kebutuhan ruana narkir di kawasan komersial ini. Pendetahuan tentano ruand narkir di nısat nerbelaniaan vano herfınnsi sebaaai referensi Derencanaaan ruana narkir vana baik di kawasan dan bangunan sanaat dinerlukan.

Contoh kasus beruna pusat berbelaniaan Jalan Taniunabura vano terletak di Kota Pontianak. ibukota Provinsi Kalimantan Barat. Pusat Derbelaniaan ini merunakan kawasan Dertokoan lama sehinoaa ketersediaan ruand narkir tidak direncanakan. Permasalahan senerti kebutuhan ruana Darkir vana melebih kanasitas danat teriadi. karena nusat nerbelaniaan memiliki tinakat aktivitas nerekonomian vana cukun tinaai sehinada kebutuhan ruana narkir iuda tinadi. Selain itu. haraa lahan vana mahal dan luas lahan vana semnit. membuat banaunan busat nerbelaniaan memiliki keterbatasan lahan. sehinaaa lahan vana diperuntukan bagi ruang parkir tidak menjadi prioritas utama.

Tujuan dari penelitian ini adalah untuk mengetahui dan menjelaskan ruang parkir di suatu pusat perbelanjaan. Metode yang digunakan dalam penelitian ini adalah metode deskriptif untuk menjelaskan teori ruang parkir dan data/fakta ruang parkir di pusat perbelanjaan parkir yang diperoleh di lapangan, serta metode kausal komparatif untuk melakukan perbandingan antar contoh kasus berupa shopping street \& department store di Pusat Perbelanjaan Jalan Tanjungpura. Metode analisis yang digunakan adalah analisis non-statistik untuk mendeskriptifkan teori parkir dan pusat perbelanjaan serta pola aktivitas dan fungsi pusat perbelanjaan, sedangkan analisis statistik untuk menganalisis karakteristik parkir, pola parkir, kapasitas jalan, dan tingkat pelayanan jalan.

\section{Kajian Literatur}

Pengertian parkir yang didefinisikan oleh para ahli sebagai berikut:

a) Parkir adalah keadaan tidak bergerak suatu kendaraan yang tidak bersifat sementara (Departemen Perhubungan Direktur Jendral Perhubungan Darat, 1996)

b) Parkir adalah tempat pemberhentian kendaraan untuk jangka waktu yang lama atau sebentar sesuai dengan kebutuhannya (Setijowarno dan Frazila, 2001).
Parkir dibedakan menjadi 2 (dua) berdasarkan lokasi penempatan parkir (Dirjen Perhubungan Darat, 1996) yaitu:

- Parkir di badan jalan (on street parking) adalah parkir kendaraan yang mempergunakan tepi jalan umum.

- Parkir di luar badan jalan (off street parking) adalah parkir kendaraan di luar tepi jalan umum yang dibuat khusus atau penunjang kegiatan yang dapat berupa tempat parkir atau gedung parkir.

Pengertian yang didefinisikan oleh para ahli sebagai berikut:

a) Kompleks perbelanjaan terencana dengan pengelolaan yang bersifat terpusat, sistem menyewakan unit-unit kepada pedagang individu, dan pengawasannya dilakukan oleh pengelola yang bertanggung jawab secara menyeluruh (Beddington, 1982).

b) Suatu tempat kegiatan pertukaran dan distribusi barang/jasa yang bercirikan komersial, melibatkan perencanaan dan perancangan yang matang karena bertujuan memperoleh keuntungan (profit) sebanyak-banyaknya (Gruen, 1973).

Berdasarkan lokasi, pusat perbelanjaan dibedakan menjadi 10 (sepuluh) jenis oleh (Marlina, 2008) yaitu:

1) Pasar (market)

2) Shopping Street

3) Shopping Precint

4) Shopping Center

5) Department Store

6) Supermarket

7) Superstore

8) Hypermarket

9) Shopping Mall

10) Town Square

\section{Karakteristik Parkir}

Menurut Munawar (2009), karakteristik parkir terdiri dari:

Akumulasi parkir adalah jumlah kendaran yang diparkír di suatu tempat pada waktu tertentu, dan dapat dibagi sesuai dengan kategori jenis maksud perjalanan.

Akumulasi $=E i-E x+X$

Keterangan:

$\mathrm{Ei}$ : Entry (kendaraan yang masuk lokasi) Ex : Exit (kendaraan yang keluar lokasi)

$\mathrm{X}$ : Jumlah kendaraan yang telah parkir sebelum pengamatan

Durasi parkir adalah rentang waktu sebuah kendaraan parkir di suatu tempat (dalam satuan menit atau jam).

Durasi $=$ Extime - Entime

Keterangan:

Extime: waktu saat kendaraan keluar dari lokasi parkir

Entime: waktu saat kendaraan masuk ke lokasi parkir

Pergantian parkir (turnover parking) 
adalah tingkat penggunaan ruang parkir dan diperoleh dengan membagi volume parkir dengan jumlah ruang-ruang parkir untuk satu periode tertentu.

Tingkat turnover $=\frac{\text { Volume Parkir }}{\text { Ruang Parkir Tersedia }}$

Indeks parkir adalah ukuran untuk menyatakan penggunaan panjang jalan dan dinyatakan dalam persentase ruang yang ditempati oleh kendaraan parkir. Indeks parkir $=\frac{\text { Akumulasi parkir } \times 100 \%}{\text { Ruang Parkir Tersedia }}$

Rata- rata durasi parkir, ditentukan oleh persamaan:

$$
D=\frac{\sum_{i=n}^{n} d i}{n}
$$

Keterangan:

$D$ : rata-rata durasi parkir kendaraan

$\mathrm{Di} \quad$ durasi kendaraan $\mathrm{ke}-\mathrm{i}$ (i dari kendaran ke-i hingga ke-n)

Jumlah ruang parkir yang dibutuhkan, ditentukan oleh persamaan:

$$
Z=\frac{Y \times D}{T}
$$

Keterangan:

$Z$ : ruang parkir yang dibutuhkan

$Y$ : jumlah kendaraan parkir dalam satu waktu

D : rata-rata durasi (satuan waktu)

$\mathrm{T}$ : lama survei (satuan waktu)

\subsection{Pola Parkir}

Sudut yang dipergunakan dalam pola parkir mobil penumpang adalah $0^{\circ}, 30^{\circ}, 45^{\circ}$ $60^{\circ}$, dan $90^{\circ}$ yang diperjelas dalam Gambar 1 (Neufert, 2002).

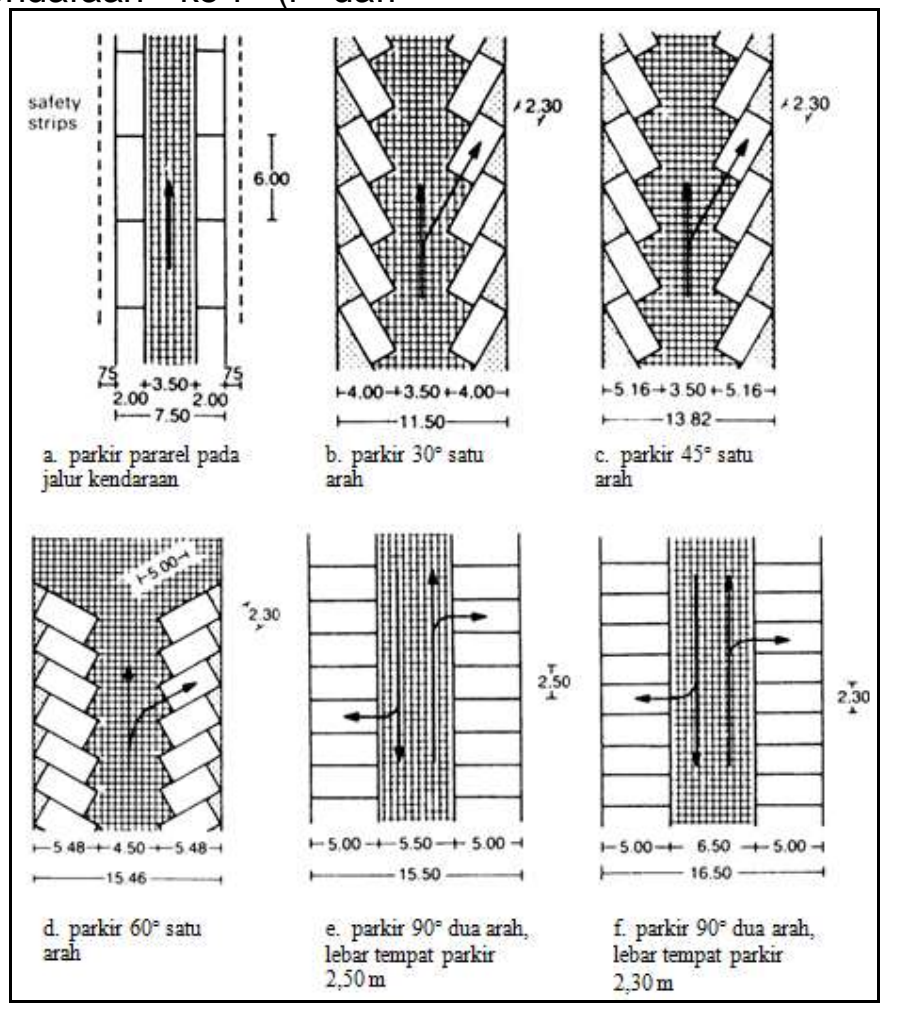

Sumber: (Neufert, 2002)

Gambar 1: Pola parkir mobil penumpang

\section{Pergerakan Kendaraan}

Aktivitas tata guna lahan dapat menarik pergerakan kendaraan yang mempengaruhi bangkitan lalu lintas (Tabel 1). Pergerakan kendaraan dapat mempengaruhi kapasitas jalan, yang dihitung menggunakan persamaan 7 . Pergerakan kendaraan juga dapat mempengaruhi jalan yang dilaluinya dengan diukur mempergunakan standar Level Of Service jalan (Tabel 8). Dalam Highway Capacity Manual Project (HCM), 1997, ditentukan rumus dasar untuk menetukan kapasitas jalan:

$$
\begin{aligned}
& C=C_{0} \times F C_{W} \times F C_{s p} \times F C_{s p} \times F C_{C S} \\
& \text { Keterangan: } \\
& \text { C : Kapasitas (smp/jam) } \\
& \mathrm{C}_{0} \quad \text { :Kapasitas dasar (smp/jam) } \\
& \mathrm{F}_{\mathrm{CW}} \text { : Faktor penyesuaian lebar jalur lalu } \\
& \text { lintas }
\end{aligned}
$$

Tabel 2, Tabel 3, Tabel 4, Tabel 5, Tabel 6, dan Tabel 7 berisikan data untuk mencari 
kapasitas dari suatu ruas jalan sesuai dengan persamaan 7 di atas. Tabel 1 , Tabel 2, Tabel 3, dan Tabel 5 merupakan tabel yang telah dimodifikasi sehingga hanya terdapat data yang dipergunakan untuk menganalisis contoh kasus.

Tabel 1: Bangkitan dan tarikan pergerakan dari aktivitas tata guna lahan

\begin{tabular}{|l|c|c|}
\hline \multicolumn{1}{|c|}{$\begin{array}{c}\text { Deskripsi aktivitas tata } \\
\text { guna lahan }\end{array}$} & $\begin{array}{c}\text { Rata-rata jumlah pergerakan } \\
\text { kendaraan per } 100 \mathrm{~m}^{2}\end{array}$ & $\begin{array}{c}\text { Jumlah } \\
\text { kajian }\end{array}$ \\
\hline Pasar swalayan & 136 & 3 \\
\hline Pertokoan lokal & 85 & 21 \\
\hline
\end{tabular}

Sumber: (Black (1978) dalam Tamin, 2000)

Tabel 2: Kapasitas dasar jalan perkotaan

\begin{tabular}{|c|c|l|}
\hline \multicolumn{1}{|c|}{ Tipe Jalan } & $\begin{array}{c}\text { Kapasitas Dasar } \\
\text { (smp/jam) }\end{array}$ & \multicolumn{1}{|c|}{ Catatan } \\
\hline $\begin{array}{l}\text { Empat lajur terbagi atau } \\
\text { jalan satu arah }\end{array}$ & 1650 & Per lajur \\
\hline
\end{tabular}

Sumber: (Highway Capacity Manual Project/HCM,1997)

Tabel 3: Penyesuaian kapasitas terhadap lebar jalur lalu lintas untuk jalan perkotaan

\begin{tabular}{|l|c|c|}
\hline \multicolumn{1}{|c|}{ Tipe Jalan } & $\begin{array}{c}\text { Lebar lajur lalu lintas } \\
\text { efektif }\left(\mathrm{W}_{\mathrm{C}}\right)(\mathrm{m})\end{array}$ & $\mathrm{FC}_{\mathrm{W}}$ \\
\hline \multirow{2}{*}{$\begin{array}{l}\text { Empat lajur terbagi atau } \\
\text { jalan satu arah }\end{array}$} & 3,00 & Per lajur \\
\cline { 2 - 3 } & 3,25 & 0,92 \\
\cline { 2 - 3 } & 3,50 & 0,96 \\
\cline { 2 - 3 } & 3,75 & 1,00 \\
\cline { 2 - 3 } & 4,00 & 1,04 \\
\cline { 2 - 3 } & & 1,08 \\
\hline
\end{tabular}

Sumber: (Highway Capacity Manual Project/HCM,1997)

Tabel 4: Faktor penyesuaian kapasitas untuk pemisahan arah ( $\left.\mathrm{FC}_{\mathrm{SP}}\right)$

\begin{tabular}{|l|l|c|c|c|c|c|}
\hline \multicolumn{2}{|c|}{$\begin{array}{c}\text { Pemisahan arah SP } \\
\%-\%\end{array}$} & $50-50$ & $55-45$ & $60-40$ & $65-35$ & $70-30$ \\
\hline \multirow{2}{*}{$\mathrm{FC}_{\mathrm{SP}}$} & $\begin{array}{l}\text { Dua lajur } \\
2 / 2\end{array}$ & 1,00 & 0,97 & 0,94 & 0,91 & 0,88 \\
\cline { 2 - 7 } & $\begin{array}{l}\text { Empat } \\
\text { lajur 4/2 }\end{array}$ & 1,00 & 0,985 & 0,97 & 0,955 & 0,94 \\
\hline
\end{tabular}

Sumber: (Highway Capacity Manual Project/HCM,1997)

Tabel 5: Faktor penyesuaian kapasitas untuk pengaruh hambatan samping dan lebar bahu di Jalan Perkotaan ( $\mathrm{FC}_{\mathrm{SF}}$ )

\begin{tabular}{|l|l|c|c|c|c|}
\hline \multirow{3}{*}{ Tipe Jalan } & \multirow{2}{*}{$\begin{array}{c}\text { Kelas } \\
\text { hambatan } \\
\text { samping }\end{array}$} & \multicolumn{4}{|c|}{ Faktor penyesuaian untuk hambatan samping dan } \\
lebar bahu FC
\end{tabular}


Tabel 6: Kelas hambatan samping untuk jalan perkotaan

\begin{tabular}{|l|l|l|l|}
\hline $\begin{array}{l}\text { Kelas hambatan } \\
\text { samping (SFC) }\end{array}$ & Kode & $\begin{array}{c}\text { Jumlah berbobot } \\
\text { kejadian per } 200 \mathrm{~m} \text { per } \\
\text { jam (dua sisi) }\end{array}$ & \multicolumn{1}{|c|}{ Kondisi khusus } \\
\hline Sangat rendah & VL & $<100$ & $\begin{array}{l}\text { Daerah permukiman, jalan } \\
\text { dengan jalan samping }\end{array}$ \\
\hline Rendah & L & $100-299$ & $\begin{array}{l}\text { Daerah permukiman, } \\
\text { beberapa kendaraan umum }\end{array}$ \\
\hline Sedang & M & $300-499$ & $\begin{array}{l}\text { Daerah industri, beberapa } \\
\text { toko di sisi jalan }\end{array}$ \\
\hline Tinggi & H & $500-899$ & $\begin{array}{l}\text { Daerah komersial, aktivitas } \\
\text { sisi jalan tinggi }\end{array}$ \\
\hline Sangat tinggi & VH & $>900$ & $\begin{array}{l}\text { Daerah komersial dengan } \\
\text { aktivitas pasar di samping } \\
\text { jalan }\end{array}$ \\
\hline
\end{tabular}

Sumber: (Highway Capacity Manual Project/HCM,1997)

Tabel 7: Faktor penyesuaian kapasitas untuk ukuran kota di jalan perkotaan $\left(\mathrm{FC}_{\mathrm{CS}}\right)$

\begin{tabular}{|c|c|}
\hline Ukuran kota (juta penduduk) & $\begin{array}{c}\text { Faktor penyesuaian untuk ukuran kota } \\
\text { FCCS }\end{array}$ \\
\hline$<0,1$ & 0,86 \\
\hline $0,1-0,5$ & 0,90 \\
\hline $0,5-1,0$ & 0,94 \\
\hline $1,0-3,0$ & 1,00 \\
\hline$>3,0$ & 1,04 \\
\hline
\end{tabular}

Sumber: (Highway Capacity Manual Project/HCM,1997)

Penentuan tingkat pelayanan suatu segmen jalan dipergunakan derajat kejenuhan (DS) yang didefinisikan sebagai rasio arus terhadap kapasitas, dengan $Q$ adalah jumlah kendaraan bermotor yang melewati jalan (smp/jam), dan C adalah kapasitas jalan.

Menurut Transportation Research

Board (1994), derajat kejenuhan (DS)

Tabel 8: Tingkat pelayanan jalan

\begin{tabular}{|c|c|l|}
\hline $\begin{array}{c}\text { Q/C } \\
\text { Rasio }\end{array}$ & $\begin{array}{c}\text { Tingkat } \\
\text { Pelayanan } \\
\text { Jalan }\end{array}$ & \multicolumn{1}{c|}{ Keterangan } \\
\hline $\begin{array}{c}0,00- \\
0,19\end{array}$ & A & $\begin{array}{l}\text { Kondisi arus bebas dengan kecepatan tinggi dan volume arus lalu lintas rendah. } \\
\text { Pengemudi dapat memilih kecepatan yang dinginkannya tanpa hambatan }\end{array}$ \\
\hline $\begin{array}{c}0,20- \\
0,49\end{array}$ & B & $\begin{array}{l}\text { Dalam zona arus stabil. Pengemudi memiliki kebebasan yang cukup untuk memilih } \\
\text { kecepatannya }\end{array}$ \\
\hline $\begin{array}{c}0,5- \\
0,69\end{array}$ & C & Dalam zona arus stabil. Pengemudi dibatasi dalam memilih kecepatannya \\
\hline $\begin{array}{c}0,7- \\
0,84\end{array}$ & D & $\begin{array}{l}\text { Mendekati arus tidak stabil dimana hampir seluruh pengemudi akan dibatasi volume } \\
\text { pelayanan berkaitan dengan kapasitas yang dapat ditolelir (diterima) }\end{array}$ \\
\hline $\begin{array}{c}0,85- \\
1,00\end{array}$ & $\mathrm{E}$ & $\begin{array}{l}\text { Volume arus lalu lintas mendekati atau berada pada kapasitasnya. Arus adalah tidak } \\
\text { stabil dengan kondisi yang sering berhenti }\end{array}$ \\
\hline$>1,00$ & $\mathrm{~F}$ & $\begin{array}{l}\text { Arus yang dipaksakan atau macet pada kecepatan-kecepatan yang rendah. Antrian } \\
\text { yang panjang dan terjadi hambatan-hambatan yang besar. }\end{array}$ \\
\hline
\end{tabular}
Sumber: (Transportation Research Board,1994)

\section{Gambaran Umum}

Lokasi penelitian adalah pusat perbelanjaan yang terletak di Jalan Taniunabura. Kota Pontianak. Contoh kasus yang diteliti terdiri dari 3 yaitu:

Shopping street ruas A terdiri dari toko Jessica Jaya (pakaian), Bintang Terang (mebel), Pertamina (kantor), dapat dihitung dengan persamaan sebagai berikut:

$$
D S=\frac{Q}{C}
$$

Mustika Jaya (mebel), Fajar Niaga (sepeda), Daya Makmur, Sinar Bintang (mebel), ruko (pakaian), Putera Jaya (sparepart), Hidup Budi (obat), Nobel Indah (tekstil), dan toko sparepart. Mobil pengangkut barang dan mobil penumpang melakukan parkir on street di pertokoan ini. Parkir kendaraan roda dua mempergunakan fasilitas parkir off street 
Pasar Tengah yang juga melayani shopping street pertokoan blok lain, sedangkan parkir di depan toko diperuntukan bagi karyawan toko dan pengunjung yang berbelanja dengan durasi parkir singkat.

Shopping street ruas B terdiri dari PD. Sinar Kota (mebel), rumah toko, Ridaco (percetakan), Mustika Maju (mebel), dan rumah. Pertokoaan ini memiliki parkir off street di beberapa toko (PD. Sinar Kota, Mustika Maju dan rumah) yang diperuntukan bagi kendaraan roda empat dan kendaraan roda dua, tetapi beberapa toko (rumah toko, Ridaco) tidak menyediakan lahan parkir untuk kendaraan roda empat sehingga mempergunakan badan jalan sebagai tempat parkir. Department store

Ramayana memiliki luas lantai $10.000 \mathrm{~m}^{2}$. Fasilitas parkir mempergunakan sistem karcis parkir dan pengunjung yang memarkirkan kendaraan sendiri. Parkir off street di bagian belakang bangunan diperuntukan bagi kendaraan roda empat dan kendaraan roda dua, sedangkan area parkir di samping bangunan diperuntukan bagi kendaraan roda empat dan di depan bangunan untuk kendaraan roda dua. Selain itu, area loading dock diperuntukan bagi kendaraan pengangkut barang melakukan aktivitas bongkar muat barang pada jam 09.00-13.00.

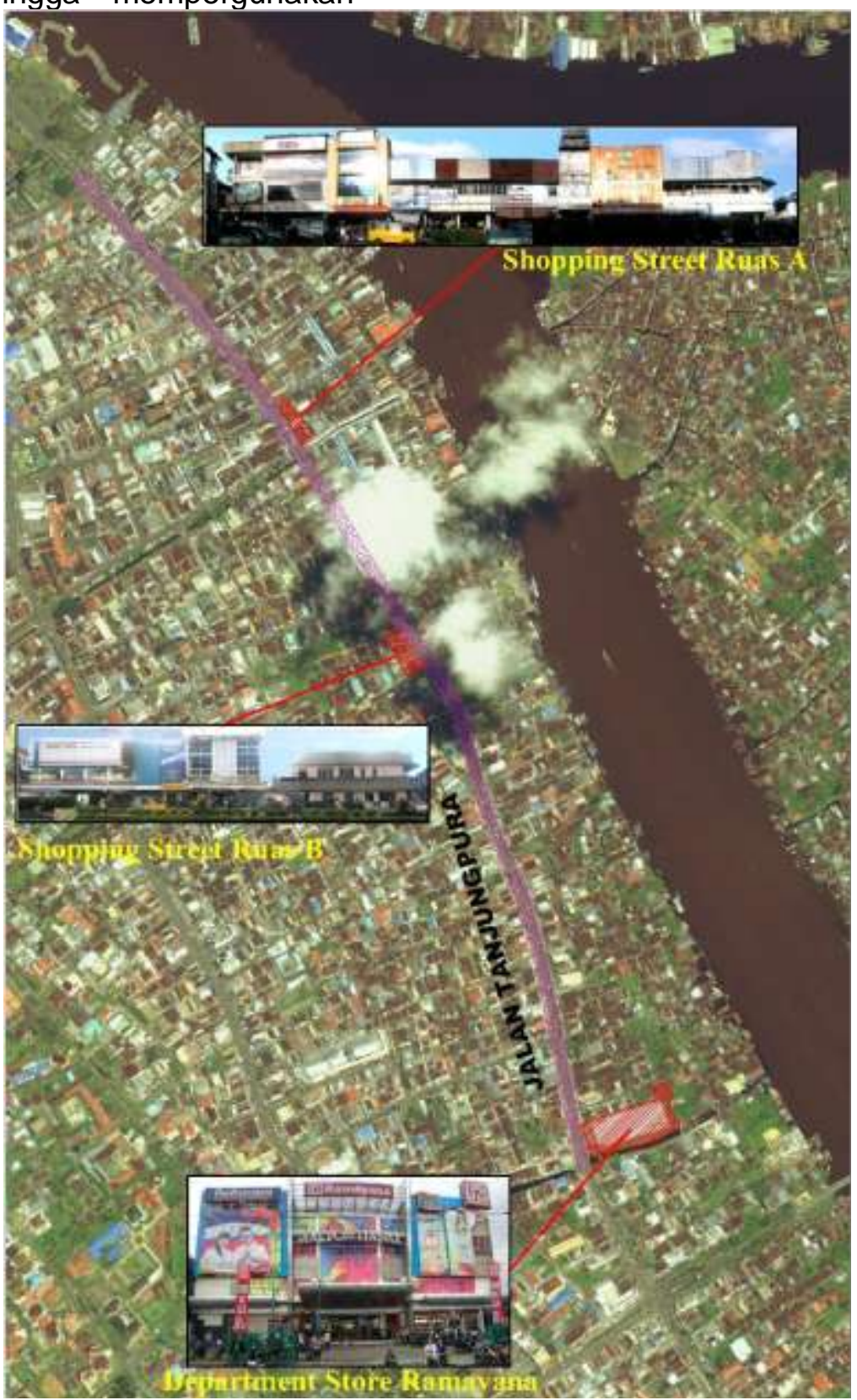

Sumber: (Hasil Survey, 2012)

Gambar 2: Peta lokasi penelitian

\section{Hasil dan Pembahasan}

Karakteristik parkir dan pola parkir di shopping street ruas A, shopping street ruas $\mathrm{B}$, dan department store Ramayana dibedakan berdasarkan jenis kendaraan yang terdiri dari kendaraan roda empat 
(mobil) dan kendaraan roda dua (motor) dalam Tabel 9. Dari tabel karakteristik dan pola parkir ini dapat dilakukan analisa yang berhubungan dengan parkir di pusat perbelanjaan yaitu fungsi bangunan-durasi parkir, pergantian parkir, pola parkirkapasitas jalan dan fungsi bangunan-LOS jalan.

Tabel 9: Karakteristik dan pola parkir dari contoh kasus

\begin{tabular}{|c|c|c|c|c|c|c|}
\hline \multirow[b]{2}{*}{ Keterangan } & \multicolumn{6}{|c|}{ Karakteristik dan pola parkir } \\
\hline & $\begin{array}{l}\text { Shopping } \\
\text { Street ruas A } \\
\text { (mobil) }\end{array}$ & $\begin{array}{l}\text { Shopping } \\
\text { Street ruas A } \\
\text { (motor) }\end{array}$ & $\begin{array}{l}\text { Shopping } \\
\text { Street ruas } \\
\text { B (mobil) }\end{array}$ & $\begin{array}{l}\text { Shopping } \\
\text { Street ruas } \\
\text { B (motor) }\end{array}$ & $\begin{array}{l}\text { Department } \\
\text { Store } \\
\text { Ramayana } \\
\text { (mobil) }\end{array}$ & $\begin{array}{l}\text { Department } \\
\text { Store } \\
\text { Ramayana } \\
\text { (motor) }\end{array}$ \\
\hline $\begin{array}{l}\text { Jumlah } \\
\text { kendaraan parkir }\end{array}$ & 16 & 47 & 16 & 21 & 14 & 51 \\
\hline $\begin{array}{l}\text { Jumlah } \\
\text { kendaraan } \\
\text { masuk }\end{array}$ & 16 & 47 & 16 & 21 & 14 & 51 \\
\hline $\begin{array}{l}\text { Jumlah } \\
\text { kendaraan keluar }\end{array}$ & 12 & 39 & 11 & 14 & 4 & 15 \\
\hline $\begin{array}{lr}\text { Jumlah } & \text { tempat } \\
\text { parkir } & \text { yang } \\
\text { tersedia } & \\
\end{array}$ & 10 & 48 & 11 & 30 & 28 & 180 \\
\hline $\begin{array}{l}\text { Jumlah } \\
\text { kendaraan yang } \\
\text { telah parkir } \\
\text { sebelum } \\
\text { pengamatan }\end{array}$ & 5 & 75 & 4 & 27 & 14 & 133 \\
\hline Akumulasi parkir & 9 mobil & 83 motor & 9 mobil & 34 motor & 38 mobil & 169 motor \\
\hline Pergantian parkir & $\begin{array}{l}1,6 \\
\text { pergantian }\end{array}$ & $\begin{array}{l}0,98 \\
\text { pergantian }\end{array}$ & $\begin{array}{l}1,45 \\
\text { pergantian }\end{array}$ & $\begin{array}{l}0,7 \\
\text { pergantian }\end{array}$ & $\begin{array}{l}0,5 \\
\text { pergantian }\end{array}$ & $\begin{array}{l}0,28 \\
\text { pergantian }\end{array}$ \\
\hline Indeks parkir & $0,90 \%$ & $1,73 \%$ & $0,82 \%$ & $1,13 \%$ & $1,36 \%$ & $0,94 \%$ \\
\hline $\begin{array}{l}\text { Rata-rata durasi } \\
\text { parkir }\end{array}$ & 7 menit & 7 menit & 8 menit & 7 menit & 19 menit & 21 menit \\
\hline $\begin{array}{lr}\text { Jumlah } & \text { ruang } \\
\text { parkir } & \text { yang } \\
\text { diperlukan } & \end{array}$ & 1,87 mobil & 5,48 motor & 2,13 mobil & 2,45 motor & 4,43 mobil & 17,85 motor \\
\hline Pola parkir & $0^{\circ}$ & $90^{\circ}$ & $0^{\circ}$ & $90^{\circ}$ & $45^{\circ}$ & $90^{\circ}$ \\
\hline
\end{tabular}

Sumber: (Hasil Survey dan Analisa,2012)

\section{Pengaruh Fungsi Bangunan-Durasi Parkir}

Grafik dalam Gambar 3 menggambarkan durasi parkir mobil barang dari ketiga contoh kasus dengan pola aktivitas toko yang berbeda-beda. Dari grafik dan pola aktivitas tersebut dapat disimpulkan parkir barang di shopping street memiliki durasi parkir yang lebih cepat karena jumlah barang yang diturunkan/dinaikkan sedikit, sedangkan department store memiliki durasi parkir yang lebih lama karena jumlah barang yang diturunkan/dinaikkan banyak. Parkir barang di toko sepeda memiliki durasi parkir yang lebih cepat karena skala barang yang diturunkan/dinaikkan kecil, dibandingkan toko mebel memiliki durasi parkir yang lebih lama karena skala barang yang diturunkan/dinaikkan besar.

Grafik dalam Gambar 4 menggambarkan durasi parkir mobil penumpang dan motor dari ketiga contoh kasus dengan pola aktivitas berbelanja di toko yang berbeda-beda. Dari grafik dan pola aktivitas tersebut dapat disimpulkan parkir pengunjung di pusat perbelanjaan shopping street memiliki durasi parkir yang relatif lebih cepat karena pengunjung datang dengan tujuan yang jelas dan terfokus, sedangkan department store memiliki durasi parkir yang lebih lama karena pengunjung datang dengan tujuan untuk berekreasi, santai dan tidak terburuburu. Parkir untuk pengunjung di toko yang menjual barang kebutuhan habis pakai (sparepart, obat) memiliki durasi parkir yang relatif lebih cepat karena barang itu dibeli ketika diperlukan sehingga tidak membutuhkan waktu memilih, sedangkan di toko yang menjual barang kebutuhan yang dapat berjangka panjang (pakaian, sepeda, mebel) memiliki durasi parkir yang lebih lama karena barang itu dapat dibeli walaupun sedang tidak diperlukan sehingga membutuhkan waktu untuk memilih barang. 


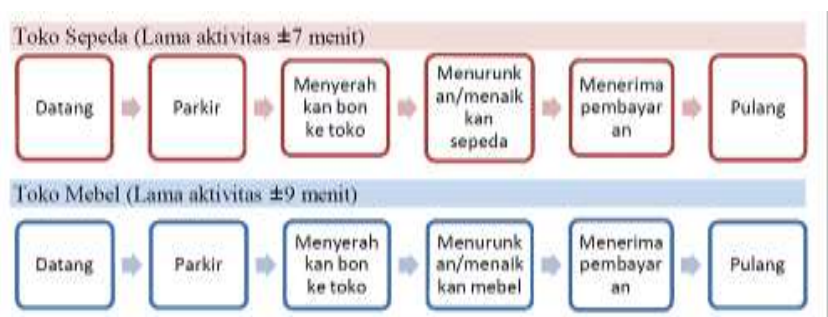

Deparment Store (Lama aktivitas \pm 240 menit)
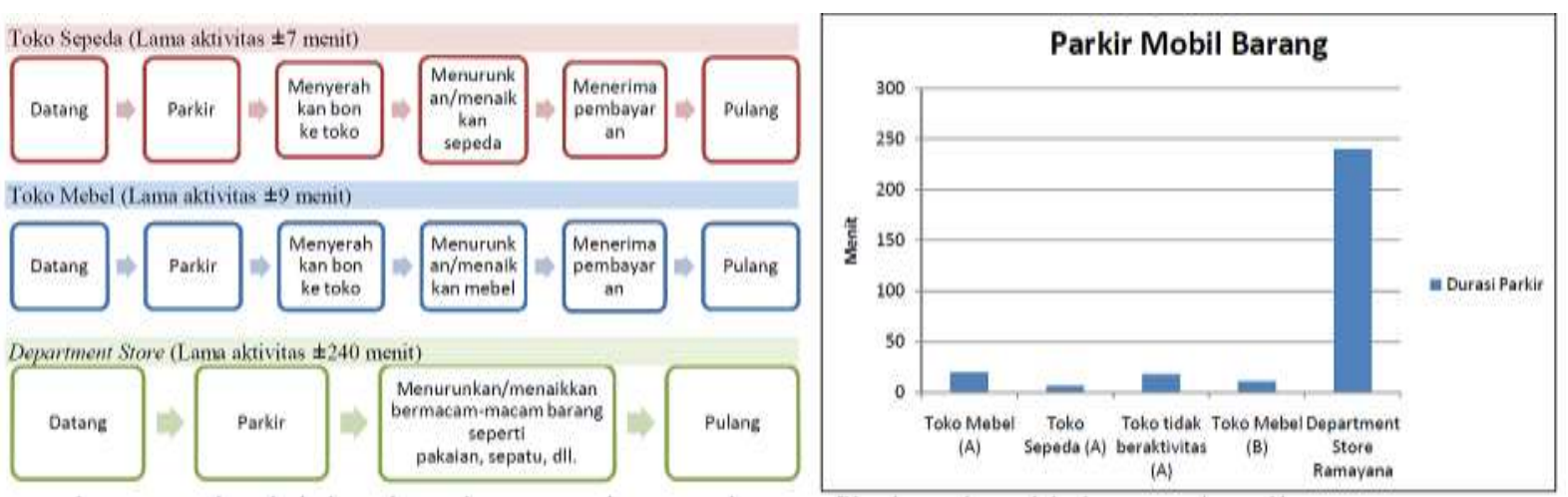

Sumber: (Analisis, 2012)

Gambar 3: Pola aktivitas bongkar muat barang dan grafik durasi parkir barang
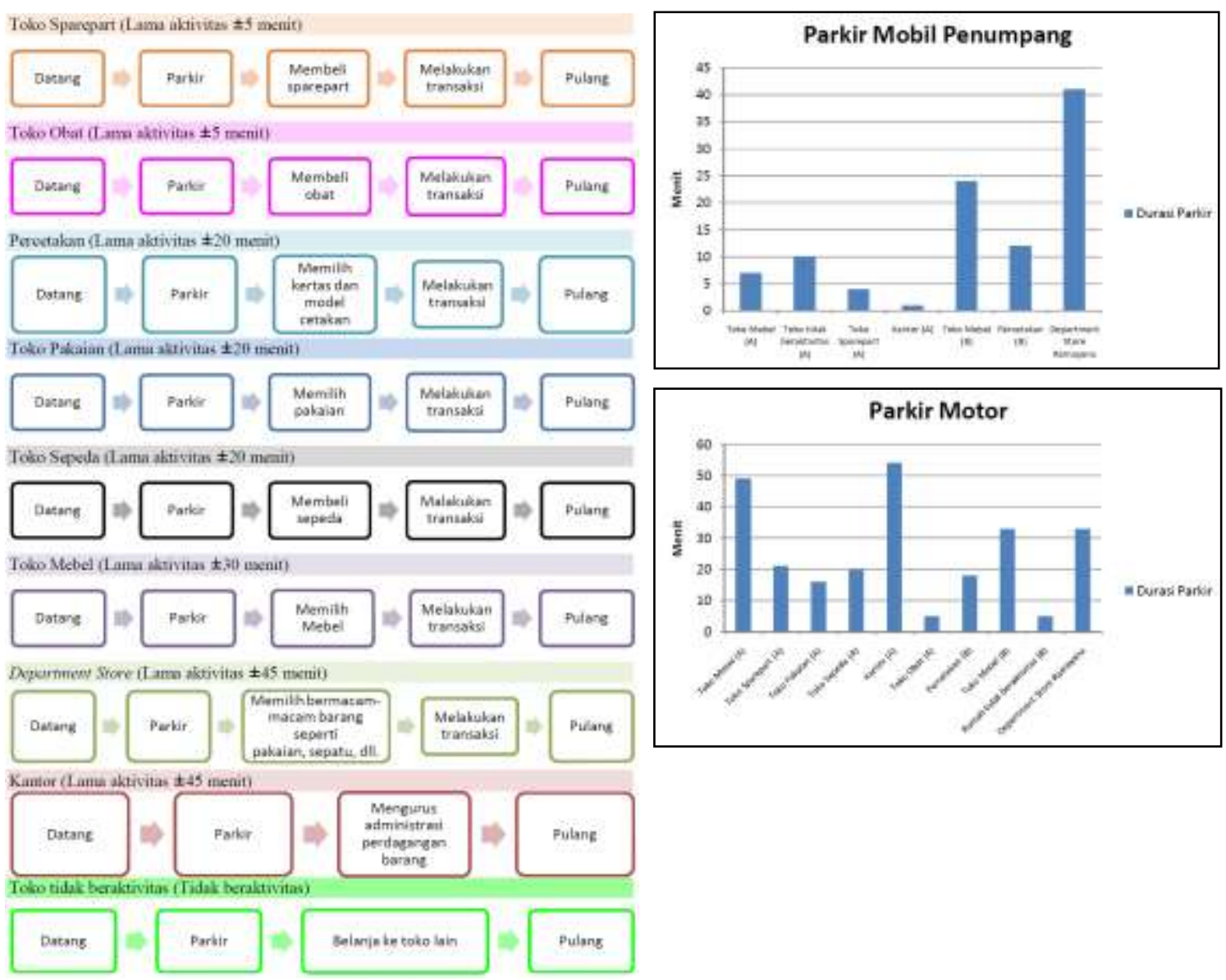

Sumber: (Analisis, 2012)

Gambar 4: Pola aktivitas pengunjung dan grafik durasi parkir penumpang

\section{Tingkat Pergantian Parkir}

Shopping street ruas A memiliki tingkat pergantian parkir mobil sebesar 1,6 pergantian dengan parkir di badan jalan (on street), parkir motor sebesar 0,98 pergantian dengan parkir di luar badan jalan. Shopping street ruas B memiliki tingkat pergantian parkir mobil sebesar 1,45 pergantian dengan parkir umumnya di badan jalan, parkir motor sebesar 0,7 pergantian dengan parkir di luar badan jalan. Department store Ramayana memiliki tingkat pergantian parkir mobil sebesar 0,5 pergantian dan parkir motor sebesar 0,28 dengan parkir di luar badan jalan. Dapat disimpulkan, tingkat pergantian parkir di shopping street A lebih besar, diikuti shopping street $\mathrm{B}$, dan department store lebih kecil (Gambar 5). 


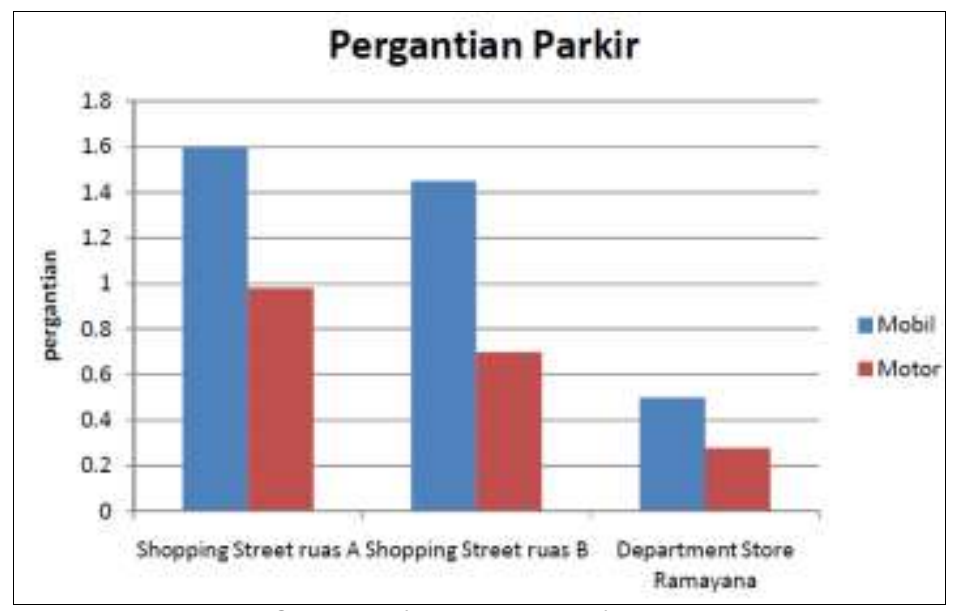

Sumber: (Analisis, 2012)

Gambar 5: Grafik pergantian parkir

\section{Pengaruh Pola Parkir-Kapasitas Jalan}

Pengaruh pola parkir terhadap kapasitas jalan dalam shopping street Ruas A, shopping street Ruas B dan department store Ramayana dijelaskan dalam tabel 10. Perhitungan kapasitas jalan dengan pola parkir di badan jalan terdiri dari tanpa parkir, parkir sudut $0^{\circ}$, parkir sudut $30^{\circ}$, parkir sudut $45^{\circ}$, parkir sudut $60^{\circ}$ dan parkir sudut $90^{\circ}$. Setiap Jalan Tanjungpura dari ketiga contoh kasus menunjukkan kapasitas jalan akan lebih besar tanpa parkir di badan jalan, dan sudut parkir dengan kapasitas jalan terbesar adalah pola parkir dengan sudut $0^{\circ}$ dalam Gambar 6 .

Tabel 10: Kapasitas jalan dari contoh kasus

\begin{tabular}{|l|r|r|r|}
\hline \multirow{2}{*}{$\begin{array}{c}\text { Pola Parkir di Badan } \\
\text { Jalan }\end{array}$} & \multicolumn{3}{|c|}{ Kapasitas Jalan (smp/jam) } \\
\cline { 2 - 4 } & $\begin{array}{c}\text { Jalan Tanjungpura Ruas } \\
\text { A }\end{array}$ & $\begin{array}{c}\text { Jalan Tanjungpura Ruas } \\
\text { B }\end{array}$ & $\begin{array}{c}\text { Department Store } \\
\text { Ramayana }\end{array}$ \\
\hline Tanpa Parkir & 5628,27 & 6566,31 & 6834,33 \\
\hline Sudut $0^{\circ}$ & 4794,45 & 5593,53 & 5821,83 \\
\hline Sudut $30^{\circ}$ & 3231,04 & 3769,55 & 3923,41 \\
\hline Sudut $45^{\circ}$ & 2240,88 & 2614,37 & 2721,07 \\
\hline Sudut $60^{\circ}$ & 1980,32 & 2310,37 & 2404,67 \\
\hline Sudut $90^{\circ}$ & 2397,23 & 2796,76 & 2910,92 \\
\hline
\end{tabular}

Sumber: (Analisis,2012)

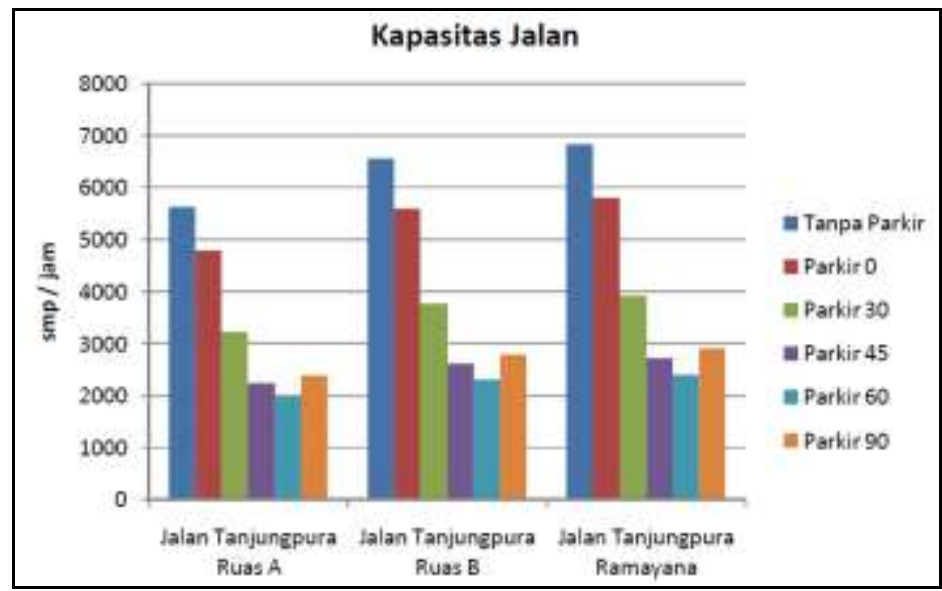

Sumber: (Analisis, 2012)

Gambar 6: Grafik kapasitas jalan terhadap pola parkir

\section{Pengaruh Fungsi Bangunan-LOS Jalan}

Pengaruh fungsi bangunan terhadap tingkat pelayanan jalan dijelaskan dalam Tabel 11. Perhitungan kapasitas jalan, disesuaikan dengan kondisi eksisting, parkir $0^{\circ}$ di badan jalan (shopping street A dan shopping street B) dan tanpa parkir di badan jalan (department store Ramayana).
Tingkat pelayanan jalan di shopping street A adalah "B". Tingkat pelayanan jalan di shopping street B adalah "A". Tingkat pelayanan jalan di department store Ramayana adalah "F". Dapat disimpulkan, pusat perbelanjaan jenis shopping street menarik jumlah pergerakan kendaraan tidak sebesar pusat perbelanjaan jenis department store, sehingga berdasarkan 
fungsi, pusat perbelanjaan jenis street.

department store berpotensi menyebabkan

kemacetan dibandingkan jenis shopping

Tabel 10: Kapasitas jalan dari contoh kasus

\begin{tabular}{|c|c|c|c|c|c|c|c|c|c|c|}
\hline Blok & $\begin{array}{l}\text { Lantai } \\
\text { Dasar } \\
\text { (m2) }\end{array}$ & $\begin{array}{c}\text { Total } \\
\text { Lantai } \\
\text { (m2) }\end{array}$ & $\begin{array}{c}\text { Tata Guna } \\
\text { Lahan }\end{array}$ & $\begin{array}{c}\text { Jumiah } \\
\text { Pergera } \\
\text { kan } \\
\text { kendara } \\
\text { an }\end{array}$ & $\begin{array}{c}\text { Panja } \\
\text { ng } \\
\text { Jalan } \\
\text { (m) }\end{array}$ & $\begin{array}{l}\text { Kelas } \\
\text { Jalan }\end{array}$ & $\begin{array}{l}\text { Lebar } \\
\text { Lajur }\end{array}$ & $\begin{array}{c}\text { Kapasi } \\
\text { tas } \\
\text { (smpj) } \\
\text { ami) }\end{array}$ & 105 & $\begin{array}{l}\text { Tingkat } \\
\text { Pelayan } \\
\text { an Jalan }\end{array}$ \\
\hline $\begin{array}{l}\text { Shopping } \\
\text { Street Ruas } \\
\text { A }\end{array}$ & 896 & 1792 & $\begin{array}{l}\text { Pertokoan } \\
\text { lokal }\end{array}$ & 1523.2 & 80.17 & $\begin{array}{l}\text { Arteri } \\
\text { Primer }\end{array}$ & 16 & $\begin{array}{l}4794 . \\
45\end{array}$ & 0.32 & B \\
\hline $\begin{array}{l}\text { Shopping } \\
\text { Street Ruas } \\
\text { B }\end{array}$ & 616 & 1232 & $\begin{array}{l}\text { Pertokoan } \\
\text { lokal }\end{array}$ & 1047.2 & 97.78 & $\begin{array}{l}\text { Arteri } \\
\text { Primer }\end{array}$ & 16 & $\begin{array}{l}5593 . \\
53\end{array}$ & 0.19 & A \\
\hline $\begin{array}{l}\text { Deportment } \\
\text { Store } \\
\text { Ramayana }\end{array}$ & 2500 & 10000 & $\begin{array}{l}\text { Pasar } \\
\text { Swalayan }\end{array}$ & 13600 & 65.22 & $\begin{array}{l}\text { Arteri } \\
\text { Primer }\end{array}$ & 16 & $\begin{array}{l}6834 . \\
33\end{array}$ & 1.99 & $F$ \\
\hline
\end{tabular}

\section{Kesimpulan}

Berdasarkan hasil penelitian dan pembahasan maka dapat disimpulkan:

- Pola aktivitas kegiatan bongkar muat barang mempengaruhi durasi parkir mobil pengangkut barang. Semakin banyak jumlah barang dan skala barang yang besar, maka durasi parkir akan lebih lama. Semakin sedikit jumlah barang dan skala barang yang kecil, maka durasi parkir akan lebih cepat.

- Pola aktivitas kegiatan berbelanja oleh pengunjung mempengaruhi durasi parkir mobil penumpang. Semakin beragam barang yang ditawarkan dan barang dapat berjangka panjang (pakaian, sepeda, mebel) maka durasi parkir akan lebih lama. Semakin terbatas ragam barang yang ditawarkan dan merupakan barang kebutuhan habis pakai (sparepart, obat) maka durasi parkir akan lebih cepat.

- Penataan tanpa parkir di badan jalan akan memiliki kapasitas jalan yang lebih besar, tetapi jika parkir di badan jalan tersedia, pola penataan parkir yang memiliki kapasitas jalan terbesar adalah pola parkir dengan sudut $0^{\circ}$.

- Pusat perbelanjaan jenis shopping street menarik jumlah pergerakan kendaraan tidak sebesar pusat perbelanjaan jenis department store, sehingga berdasarkan fungsi, pusat perbelanjaan jenis department store berpotensi menyebabkan kemacetan dibandingkan jenis shopping street.

- Jenis parkir on street di pusat perbelanjaan shopping street memiliki tingkat pergantian parkir yang besar dibandingkan dengan jenis parkir off street di pusat perbelanjaan department store.

- Terdapat faktor asal-tujuan pergerakan kendaraan yang juga dapat mempengaruhi tingkat pelayanan jalan.

\section{Ucapan Terima kasih}

Ucapan terima kasih disampaikan kepada:

- Dinas Perhubungan dan Department Store Ramayana Pontianak yang membantu memberikan data

- Mahasiswa Arsitektur 2010 (Carla Jayanti, Winda, dan Ismail) atas bantuan dalam Penelitian Arsitektur ini.

\section{Referensi}

Beddington, Nadine. 1982. Design For Shopping Centres. London: Butterworth Scientific.

Departemen Perhubungan Direktur Jendral Perhubungan Darat. 1996. Pedoman Teknis Penyelenggaraan Fasilitas Parkir. Jakarta: Departemen Perhubungan Direktur Jendral Perhubungan Darat.

Directorate Of Urban Road Development. 1997. Highway Capacity Manual Project (HCM). Jakarta: Directorate General Bina Marga.

Gruen, Victor. 1973. Centers For The Urban Enviroment: Survival Of The Cities. New York: Van Nostrand Reinhold Co.

Hakim, Rustam dan Hardi Utomo. 2003. Komponen Perancangan Arsitektur Lansekap. Jakarta: PT. Bumi Aksara.

Marlina, Endy. 2008. Panduan Perancangan Bangunan Komersial. Yogyakarta: Andi

Munawar, Ahmad. 2009. Manajemen Lalu Lintas Perkotaan. Yogyakarta: Beta Offset

Neufert, Ernest. 2002. Data Arsitek Jilid II Edisi 33. Jakarta: Erlangga.

Setijowarno dan Frazilia R.B. 2001. Pengantar Sistem Transportasi. Semarang: Unika Soegijaprata.

Tamin, Ofyar Z. 2000. Perencanaan dan Permodelan Transportasi, Edisi Kedua. Bandung: Institut Teknologi Bandung.

Transportation Research Board. 1994. Highway Capacity Manual, Third Edition Special Report 209. Washington D.C: National Research Council.

Warpani, Suwardjoko. 1988. Rekayasa Lalu Lintas. Jakarta: PT. Bhratara Niaga Media 